\title{
Advantages and challenges of using mobile ethnography in a hospital case study: WhatsApp as a method to identify perceptions and practices
}

\author{
Thomas Bjørner, ${ }^{1}$ Morten Schrøder ${ }^{2}$ \\ ${ }^{1}$ Department of Architecture, Design and Media Technology, Aalborg University, Copenhagen; ${ }^{2}$ Wilke, Copenhagen, Denmark
}

\begin{abstract}
The focus of this article is to provide the reader with reflexivity and a framework for using mobile ethnography. Based on a case study with an ethnographic approach (including mobile ethnography using WhatsApp), we identified perceptions and practices for improved workflows and procedures related to nurses' introduction and implementation of self-catheterization at the National Spinal Injuries Centre in Great Britain. We offer detailed procedures, advantages, and challenges in using mobile ethnography. The ethnographic approach consisted of four phases, including initial workshops, go-along observations, interviews, and a mobile ethnographic approach using WhatsApp as a mobile diary for six nurses. Within the case study, three major themes were revealed by the ethnographic approach, with the conclusion that nurses have positive attitudes towards self-catheterization, but these nurses are becoming less influential and the practices around this technique are consequently disappearing. The main result is that use of WhatsApp as a self-tracking tool can extend the methodological toolbox, but reflexivity and preliminary work are required to make the practice beneficial.
\end{abstract}

\section{Introduction}

Patient care quality and communication are central elements for nurses helping patients recover optimal health

\footnotetext{
Correspondence: Thomas Bjørner, Department of Architecture, Design and Media Technology, Aalborg University, A. C. Meyersvænge 15, 2450 Copenhagen SV, Denmark.

Tel.: +45.61144601.

E-mail: tbj@create.aau.dk

Key words: Mobile ethnography; Interviews; WhatsApp; Workflows.

Acknowledgements: acknowledgement to Rie Lykke Danielsen, Perspectives Consultant, Lead ethnographer, Wilke, Overgaden neden Vandet 9C, 1414 Copenhagen K.

Contributions: TBJ wrote the manuscript and was responsible for the overall theoretical framework and the academic validity. MS was the case study project leader and was responsible for permissions, stakeholder communication, the overall study design, data collection, and analysis. TBJ and MS revised the manuscript critically for important intellectual content.
}

Conflict of interest: the authors report grants from BRANDBASE, Denmark, and grants from Coloplast, during the conduct of the study.

Funding: this work was supported by the project Qual Roadmap, BRANDBASE, Denmark.

Received for publication: 30 August 2018.

Revision received: 11 June 2019.

Accepted for publication: 11 June 2019

This work is licensed under a Creative Commons Attribution NonCommercial 4.0 License (CC BY-NC 4.0).

${ }^{\circ}$ Copyright: the Author(s), 2019

Licensee PAGEPress, Italy

Qualitative Research in Medicine \& Healthcare 2019; 3:58-67

doi:10.4081/qrmh.2019.7795 and quality of life. Nurses often coordinate and engage in patient care in multidisciplinary health care teams, including doctors, therapists, medical practitioners, medical consultants, and dietitians. Yet, while interest in nurses' workflows and procedures within these multidisciplinary teams has grown, little process has been made using mobile ethnography to methodologically improve insights into perceptions, culture, and practices within very specific workflow contexts. The research question within this study is as follows: What are the advantages and challenges of using mobile ethnography in a hospital case study, where the case study aim is to identify perceptions and practices for improved workflows and procedures?

\section{The descriptive case study}

A case study is an empirical inquiry that investigates a contemporary phenomenon in depth within its real-life context. ${ }^{1}$ We have used this descriptive case study ${ }^{1}$ to describe a phenomenon in context, including rich descriptions of the context and case and detailed information on the methodological framework. Within this framework, contextual factors are dynamic constructs that surround nurses workflows, taking both time and space into account. ${ }^{2-29}$ In this section, we introduce the context and case, and in the following sections, we focus mainly on the methodological ethnographic framework. Our descriptive case study took place at the National Spinal Injuries Centre, Stoke Mandeville Hospital in Great Britain.

The aim of the case study was to identify perceptions and practices for improved workflows and procedures within nurses' use and introduction of self-catheterization at the National Spinal Injuries Centre. It is reported that self-catheterization has a positive impact on patients' quality of life, including reduced mortality and 
morbidity, improved urinary symptoms, reduced incontinence, fewer infections and complications, better sleep, increased independence and self-confidence, and maintaining a normal sex life. ${ }^{2,3}$ However, rates of selfcatheterization $(10 \%)$ at the National Spinal Injuries Centre are significantly lower than the target of England's National Health Service, which is $80 \%$. The case study used an ethnographic approach to understand the reasons behind this relatively low rate of self-catheterization use and to determine meaningful ways of substantially increasing these rates (up to 50\%) in bladder management. The National Spinal Injuries Centre has established an international reputation for quality services, including international accreditation for excellence in the care of adults and children with spinal cord injuries. The unit offers diagnosis, treatment, follow-up, and rehabilitation for patients with acute spinal cord injuries and non-traumatic spinal cord lesions of acute onset. Patients are referred to this unit from all over the United Kingdom and from many countries around the world. Most patients are admitted to the spinal unit due to traumatic injuries, typically via the hospital's accident and emergency unit or from another hospital. Due to their spinal injuries, these patients often have bladderemptying problems; for many, self-catheterization can be a safe and effective way of managing these problems. Other authors have stated that having patients use selfcatheterization (and preventing self-catheterization complications) requires education and training, patient compliance, and suitable catheter material. ${ }^{2-4}$ On the other hand, a lack of time for nurses is a well-known barrier to proper patient education and training. In a previous survey, $70 \%$ of nurses stated that they had $45 \mathrm{~min}$ or less to teach patients self-catheterization, ${ }^{5}$ which many stated was inadequate to train their patients properly. Previous literature ${ }^{7-9,28}$ has outlined how mobile ethnography can be used to identify perceptions and practices, which has mainly been used for mobility and tourism research; mobile ethnography for improved workflows and procedures in health care has been insufficiently researched.

\section{Mobile ethnography in health care}

Mobile ethnography emerged in the late 1990 s as a method to track strategies for complex studies. ${ }^{6}$ Scholars have agreed that mobile ethnography emphasizes movement, but they have used and defined this concept differently, with various opinions on what should be at the center of the analysis. In this article, we are in line with other scholars' definitions; mobile ethnography should be understood as ethnography using a mobile device. ${ }^{7}$ As Hein et al. ${ }^{8}$ suggested, mobile devices can act as extensions of ethnographers and allow them to record observations, co-create data, and share experiences with participants. However, it is very important to think about not only how mobile devices can be applied but how they can be used to solve specific research questions and how they fit into the wider context of a health care study, including the ontological and epistemological implications of using mobile technology.

Within the case study, the aim was to identify perceptions and practices for improved workflows and procedures within nurses' introduction and use of self-catheterization in a hospital context. Perceptions are complex constructs, so they cannot be measured directly (e.g., as quantitative workflows); rather, one must rely on inference. In this study, perceptions are understood as being composed of affective (feelings), cognitive (beliefs), and behavioral (actual) actions, similar to how Spooncer defined attitudes..$^{10}$ Practices are understood as being micro perspectives, ${ }^{11,12}$ which can be used to explain the complex relationships between nurses' actions (including what they say and do) and the system (including space, culture, organization, and norms) within a workday context. Previous literature demonstrates that ethnography has been used to examine general perceptions and practices $^{6,12,23}$ as well as applied nursing perceptions and practices. ${ }^{13,14}$ Scholars have focused on how to approach hospitalized patients' perceptions and various new applications of digital technologies that facilitate these perceptions. ${ }^{15-19}$ However, nurses and other health care staff members increasingly must provide feedback about their health care experiences to improve patient care quality. ${ }^{15,20}$ A common focus is on workflows; this underlines an understanding that operational efficiency can be quantitatively evaluated using flow with linked elements of, for example, travel distances, interruptions, and time. . $^{18,21,22}$ However, when exploring dynamic nursing activities, the tasks performed within quantitative workflows might not provide a comprehensive picture, and further supplementary methods are needed to support in-depth insights and strengthen applied implementations. ${ }^{18}$ At the same time, a more triangulated qualitative approach to workflows is rather complex. Health care staff members often find it difficult to provide this feedback because it can be difficult to identify one's workflows and because descriptions are often based on selective memory experiences. ${ }^{20}$

Mobile ethnography, instead, can collect data in nondigital unbounded environments, with the benefit of collecting the data in an unobtrusive way on-site and at the time of specific activities of research interest. To be more specific, mobile ethnography can be implemented as a methodological tool for examining what and how humans do things in context. Several scholars emphasized the importance of triangulation as a way to improve qualitative validity. ${ }^{9,24,30-33}$ One of the common critiques of interviews is that they place too much focus on what the participants say they do - not what they actually say and do. This is partly because there can be significant differences between what participants do in practice and what they say they do in interviews and partly because most everyday practices are unintentional and habitual. 


\section{Materials and Methods \\ Participants and sampling}

We recruited six nurses and four patients from the National Spinal Injuries Centre, Stoke Mandeville Hospital via purposive sampling. We collected the data over a period of 2 months. For inclusion, the nurses had to serve in different wards, have different competencies, and treat patients at various stages of the rehabilitation process. We excluded non-English-speaking nurses and those with low seniority. For inclusion, the patients had to be hospitalized and able to participate in an interview, meaning that they were not too vulnerable.

\section{Procedure}

This study was field-based and used an ethnographic approach inspired by the frameworks of Pink ${ }^{12,23}$ and Atkinson and Hammersley. ${ }^{24}$ The ethnographic approach has the advantages of focusing systematically on specific contexts (in this case, the context of self-catheterization treatment) and strengthening the subsequent analysis through the use of various sources of data. This study consisted of four phases (Figure 1), including some methods for implementing triangulation in the ethnographic approach. ${ }^{24,25,29}$

Phase 1

We arranged a kickoff workshop at the National Spinal Injuries Centre to meet the management and staff and agree on the setup. We then initiated recruitment and the planning of the subsequent phases.

\section{Phase 2}

We arranged go-along observations ${ }^{30}$ to follow six nurses during their shifts, particularly to observe the selfcatheterization context and practices; we also intended to specify and phrase the questions in Phase 3. Researchers followed individual nurses on their shifts, asked questions, listened, and observed to explore the nurses' duties, perceptions, and practices regarding self-catheterization. After the go-along observations, we interviewed the six nurses following a semi-structured interview guide. ${ }^{9} \mathrm{We}$ specified in the interview guide that the interviewer should use information from the go-along observations to enhance the questions. The interviews lasted between 45 and 90 minutes. Further, we interviewed four patients to

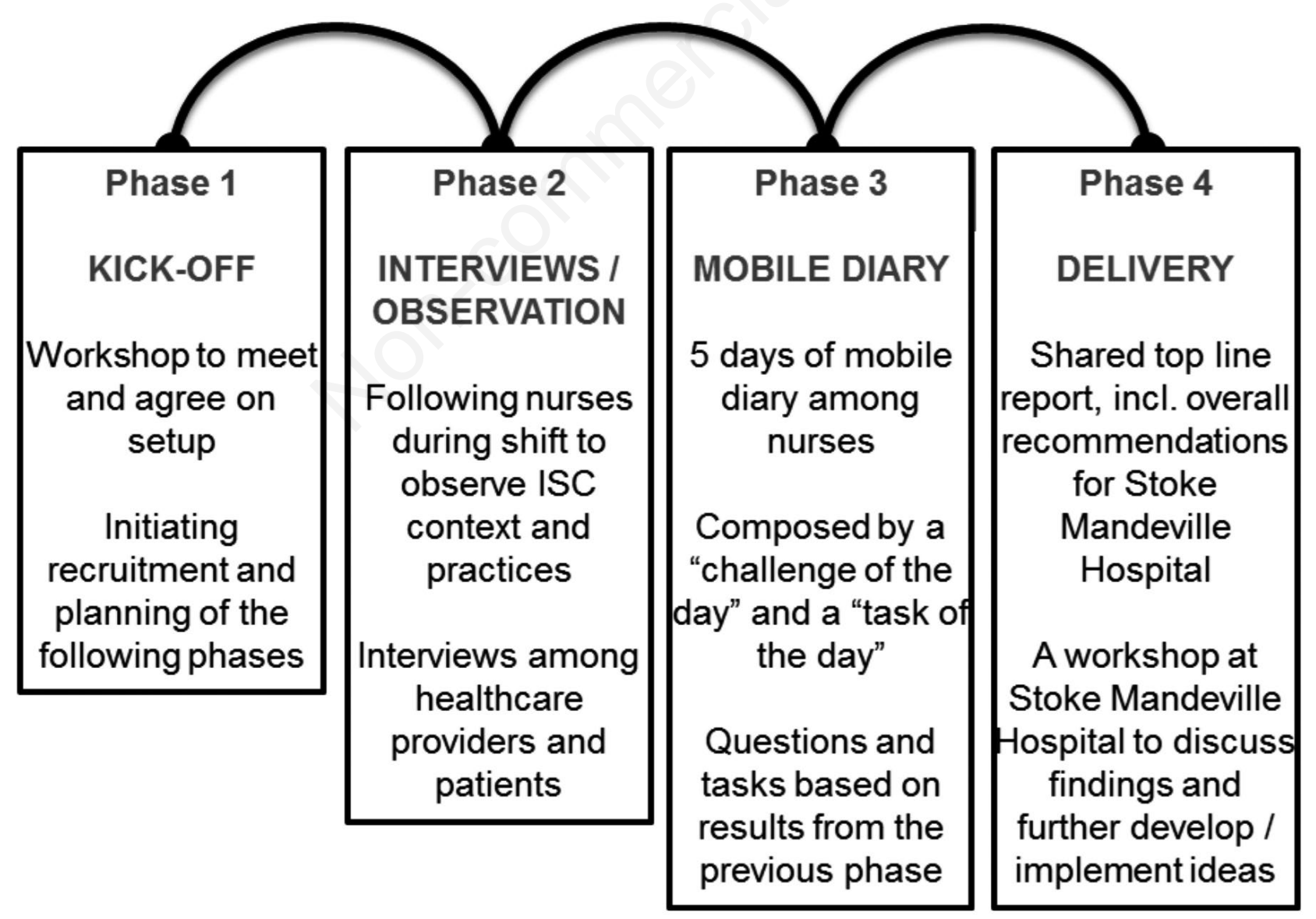

Figure 1. A study flow with 4 phases. 
provide a broader picture and more detailed information from the patients' point of view. The interviews lasted approximately 60 minutes and used storytelling as the main interview technique. ${ }^{9}$

\section{Phase 3}

We acquired 5 days of mobile diary data from six nurses using WhatsApp, which included a challenge of the day and a task of the day. We based the questions and tasks on the results from the previous phases. Detailed information about the procedure within this phase is outlined in the subsection titled WhatsApp for Data Collection and Self-Tracking.

\section{Phase 4}

We reported recommendations for Stoke Mandeville Hospital and organized a workshop to discuss the findings related to self-catheterization and how to develop and implement ideas.

\section{WhatsApp for data collection and self-tracking}

For Phase 3 (Figure 1), we used WhatsApp to facilitate data collection and provide the mobile diary. Researchers have previously used WhatsApp in health care studies, ${ }^{26,27}$ but few have used it in classic diary studies of nursing practices. Before choosing WhatsApp as the specific tool for our study, we considered various ethnographic mobile opportunities, including the ethOS, Over the Shoulder, Indeemo, and Mindwarms apps. However, the main advantage of WhatsApp was that the included participants were already familiar with using it. It would have been time consuming for the participants to establish knowledge and skills using a new app, and this study was slated for a relatively short period of time among a very busy staff. Additionally, WhatsApp is a freeware app that performs fast two-way communication and uses end-to-end encryption technology, which allows for data between communicating parties to be secure. ${ }^{31}$ Furthermore, WhatsApp can be used on multiple platforms.

WhatsApp can be used similarly to a classic diary, but it has added support because it is used on a smartphone. Six nurses documented their mobile experiences in situ using WhatsApp. In this method, also labeled self-tracking, ${ }^{17}$ nurses act as researchers and report their experiences using their smartphones. Following the WhatsApp posts, we could reconstruct the nurses' accounts of care through the stages of the self-catheterization process. Prior to beginning their mobile diaries, the nurses read our instructions. They all used their own mobile phones and were familiar with WhatsApp. Each day, they received a specific task and accompanying questions, listed below in a condensed format.

\section{Day 1}

Please photographically document the self-catheterization training facilities (location), self-catheterization training equipment (catheters and other relevant items), and written self-catheterization information (leaflets or other relevant documents, including illustrations), as well as the individual timetables at the patients' beds (e.g., 35 examples; patients' identities can be left out). Capture examples of delays in relation to bladder management and self-catheterization specifically.

\section{Day 2}

In Phase 2 (Figure 1), we learned that there is a challenge related to definitive self-catheterization dismissal in the early stages of the patient journey (acute and early rehabilitation). What are your thoughts on this? What could counteract the described self-catheterization barrier? Please take some time to discuss self-catheterization with your colleagues and collect their perceptions; summarize their responses here. If you and your colleagues are comfortable with it, please audio or video record your conversations with your phones and upload the recordings to the app.

\section{Day 3}

In Phase 2 (Figure 1), we learned that there are challenges related to the limited number of self-catheterization ambassadors. What are your thought on this? How can the concept of dedicated self-catheterization ambassadors be strengthened? What should be prioritized in the short and long run? Please illustrate the typical patient journey, including the courses of treatment related to bladder management. Use as much detail as you can; then photograph this chart and upload it to the app.

\section{Day 4}

In the previous research phase, we learned that there is a challenge related to patient pushback when considering or actively switching to self-catheterization and that at least some nurses (particularly less experienced ones) find it hard to challenge patients' views when they do not coincide with their own. What are your thoughts on the above? What are the main reasons for this patient pushback, and how can it be better counteracted in a respectful way?

Please take some time to discuss self-catheterization and this challenge with your (relevant) patients to collect their perceptions on the matter (ideally, two to three views); summarize the responses here. What are their worries and barriers related to self-catheterization (physical, psychological, social, etc.), and how do they feel those concerns could be dealt with in a respectful way?

\section{Day 5}

We learned in the previous phase that there is a challenge related to siloed thinking across wards. What are your thoughts on this? What could be done to better link the wards and the stages of the patient journey? Please be as specific as possible, including examples or suggestions. 
Before we say goodbye, we would like to better understand what your typical workday is like. We would thus like you to spend the day logging your activities and tasks. Before the end of your shift, consider two things. First, was this a typical working day? If not, what would it typically look like? Second, describe in detail any disturbances, delays, tensions, and so on that you felt during the shift, particularly those in relation to self-catheterization. Help us understand what could be done to avoid such issues in the future.

\section{Ethical considerations}

We gave all participants anonymized names and identification numbers. We took into account the special ethical considerations appropriate to interviewing and observing at a hospital, following the International Code of the International Chamber of Commerce and ESOMAR. ${ }^{25}$ We acquired legal access, permission, and written consent from the National Spinal Injuries Centre and Stoke Mandeville Hospital. Furthermore, we made special considerations when interviewing patients to make sure that they were capable of making informed decisions and were not unduly pressured to cooperate with the research request. Patients were recruited via referrals from the health care staff. Before contacting patients, researchers contacted and explained the research procedures and recruiting criteria to nurses, emphasizing that participants' responses were anonymous and confidential and their right to refuse to participate without jeopardizing treatment. The selected patients were informed by the researcher that the interview was voluntary, and they could drop out at any time. Further, it was specified in the interview guide that the interview could be shortened if the patients started to feel tired, either according to the patients' statements or the researchers' judgement.

\section{Analysis}

The WhatsApp data and nurse and patient interviews were analyzed by traditional coding ${ }^{9,32}$ following four steps: organizing, recognizing, coding, and interpretation. The first step was to organize and prepare the data for analysis. The interviews from nurses and patients were transcribed verbatim, and the visual materials were catalogued. The next step was recognizing; transcriptions were read several times by two researchers to establish the concepts and themes. This second step provides a general sense of the information and opportunity to reflect on its overall meaning. ${ }^{32}$ The third step was coding, during which researchers organized and labelled the data in categories/subcategories. Various topics were clustered to avoid having too many categories. The last step was interpretation, which included an analysis of the categories using a question from Creswell ${ }^{132}$ (What lessons have we learned?) and consideration of the terms of a workflow journey from point $\mathrm{A}$ to point $\mathrm{B}$.

\section{Results and Discussion}

\section{Advantages of using WhatsApp as a mobile ethnography tool}

Compared to classic ethnography, such as go-along methods, the six nurses used WhatsApp as part of the ethnographic data collection, which provided several advantages.

\section{Researcher not present}

The researcher was absent, which minimized the bias and presence in situ. This probing method provided the nurses with time to reflect upon the tasks and questions without disturbance from the researcher.

\section{Timing and reduced recall bias}

This mobile ethnographic method improved the data by taking advantage of ubiquitous mobile technology. WhatsApp provided rapid communication in challenging scenarios, meaning that the documentation (text, photos, or videos) happened immediately (at the touch points) or shortly after (within the same day) - whenever the nurses had time. This immediate documentation minimizes recall bias, and dates and times were automatically registered and stamped.

\section{In-depth information}

The study's WhatsApp data provided lots of contextual information, which allowed for more detailed information about the situational context than, for example, an interviewer could gather alone.

\section{Informal communication}

An interesting result was that communication via WhatsApp involved an instant messaging thread between the participants and the researchers. The continuity in the communication was provided through fast text messages. Furthermore, this communication was informal and friendly, with messages such as have a nice weekend or sorry, I will continue tomorrow, as well as the use of emojis.

\section{Familiarity}

The nurses were already used to WhatsApp, which provided confidence with the platform.

\section{Engaged participants}

The participants showed high engagement as soon as the communication and documentation started. This could be due to the participants' use of their own smartphones but might also be because the nurses' personalities made them particularly well-suited to helping others (compared to people in other professions). 


\section{Spanning geography}

The researchers were somewhere else (in another country) as the data collection through WhatsApp took place. However, the possibility of support was present if the nurses required it during the data collection.

\section{Economic efficiency}

As the researchers did not need to be located in situ, this study was rather economically efficient. Furthermore, this method facilitates research on a large number of individuals simultaneously, which also lowered the costs.

\section{Challenges of using WhatsApp as a mobile ethnography tool}

Some challenges developed in using WhatsApp for data collection are listed below.

\section{Preparation}

This mobile ethnographic method demanded much preparation from both the researchers and the participants. The nurses needed instructions as to what information they should collect and which events they should document as well as how and why they should do so. Thus, researchers were attentive and made sure that the participants understood their tasks. Mobile ethnography is a self-documentation method; the researchers were not present in situ to guide the nurses, so the instructions needed to be very clear. There were almost no instances of questions from nurses regarding the specific instructions, though there were some questions about how much they should document.

\section{Order and structure}

One of the main conclusions from this study is the importance of reflexivity and strategy in terms of ensuring that the study design and phase execution made sense for the nurses. In particular, it was time consuming to construct the right tasks for today and the accompanying questions related to the events taking place during a normal workday for the nurses. Therefore, the go-along observations were very beneficial before initiating the specific mobile ethnography.

\section{Limited amount of data}

The information received was informative but rather brief. This means that the method did not capture hidden elements or provide significant depth, establishing limitations of data depth and the structure of the software itself. Therefore, it is important to use triangulation to supplement the WhatsApp data (e.g., through interviews).

\section{No nonverbal communication}

Face-to-face interactions did not occur in this method, so some important nonverbal communication is missing.

\section{Ethical concerns}

Even though WhatsApp provides secure and end-toend encryption of all data transmitted through the application, particular attention must be paid to ensuring the protection of personal data. In this study, we double secured all the data; furthermore, we had very strict rules about taking photos only of objects, not of persons (either staff members or patients).

\section{Researcher-participant distance}

A common well-described element within qualitative research is the importance of the researchers' position in interaction with participants. ${ }^{6,824,32}$ This includes the concept that researchers may influence the research and the findings, which requires reflexivity. Within this study, there are several issues requiring further reflexivity in regard to researcher-participant relationships. First, nurses may have been more willing to share their experiences due to their tendency toward helpfulness as nurses and/or a perceived sympathetic communication with the researcher, which included elements outside the specific today's tasks and research questions. This included texted greetings from the nurses, such as Hi, Good morning, Good night, Sleep well, Have a nice day, Have a nice weekend, and $B 2 W$ (back to work). There were also instances of perceived guilt when not providing data, e.g., Sorry, I will continue tomorrow, Sorry, but a rather busy day, and I promise to feed in tomorrow. Many of these text messages were also followed by emojis, which expressed nurses' emotional states and could be seen as compensation for the missing nonverbal communication. These friendly messages also shaped the nature of the researcher-researched relationship, which in turn affected the information that the nurses are willing to share. Informal communication supported trust, which also could mean that the nurses were more comfortable discussing and sharing information. However, it is important to maintain reflexivity in data collection phases, meaning that the development of trust still fell within a researcherparticipant (data collection) relationship. It would be both awkward and impolite if the researcher did not respond to these informal communication elements, though all the messages were responded to in a polite, formal way. This means that the replies avoided eliciting further emotional states from the researcher (both in text and signs, including emojis) and common friendly text/chat abbreviations (e.g., U2). The replies were more like encouragements for further data-collection engagement, such as No worries. Looking forward to your potential texts and photos tomorrow.

These were the specific advantages and challenges of using WhatsApp as a methodological tool; in the following subsections, we proceed with the results within casespecific elements.

\section{Time and space for training}

The results of this study reveal that nurses at National 
Spinal Injuries Centre often have very positive attitudes toward self-catheterization. There was also consensus that patients' successful use of self-catheterization requires patient education and training. Bladder management (including self-catheterization) at the National Spinal Injuries Centre is a relatively small part of the staff's remit, and this involvement is subsequently often lower in priority than other tasks. Even among the nurses and health care assistants who are most involved in bladder management, this area presumably only represents $5-10 \%$ of daily tasks. However, perceptions of bladder management and practices do vary across wards, typically with increased involvement and relevance as the patient journey progresses. The patient journey includes four main steps: Acute ward, rehabilitation, pre-discharge, and outpatient. For physiological reasons, most patients in the acute ward are not well-suited to self-catheterization training or use, so their transfer to rehabilitation is often thought of as the decisive moment when self-catheterization training begins. However, once in rehabilitation, selfcatheterization training often competes with numerous other activities for the patients' (and nurses') time. Physiotherapy and occupational training, in particular, seem to have a higher priority than bladder management, which has to be scheduled around these activities rather than holistically integrated into the rehabilitation program or paced to suit the patient. One nurse concluded:
On weekdays, the patients attend their physiotherapy and occupational therapy appointments and are usually tired when they come back. There are a lot more disturbances and tension. On weekends, we have time to breathe, have a chat with the patients and catch up on paperwork and teaching (WhatsApp, ID 1503).

This means that patients were often left to train either late in the day or on weekends, when they were likely to be tired and when a competent self-catheterization nurse was less likely to be available. Another element that was revealed from the photos taken on WhatsApp was the specific training facilities (Figure 2), which could be documented as scarce and improvised. Offices, private rooms and toilets were used as available but did not necessarily provide the best intimate spaces. There were also photos taken on WhatsApp documenting various staff communications, including information boards. However, several of the nurses found it very difficult to find the time for staff education; the information boards were available across wards, but it was equally hard to find time to update these information boards.

A patient must be able to self-catheterize from the start, as staff members cannot be dedicated to catheterizing patients regularly. This means that patients' training, and psychological and physiological issues push selfcatheterization back to a much later stage in the process,
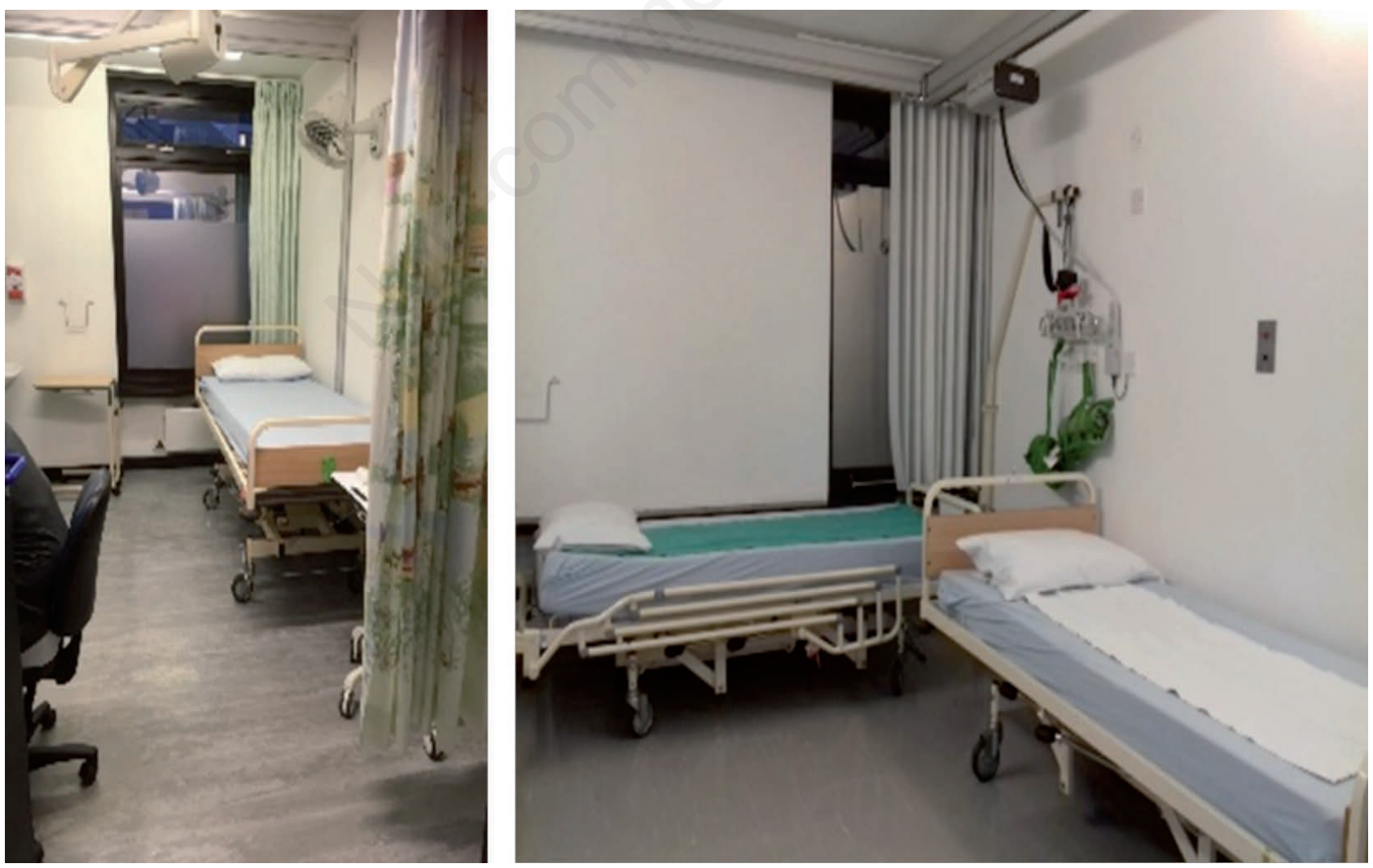

Figure 2. Example of WhatsApp photos of facilities. 
reducing the length of the period when the patient is allowed to get comfortable with self-catheterization. Nurses self-reported spending around 30 minutes to one hour each day dealing with catheters (longer when there were problems such as blockages) during each 12-hour shift. The bulk of their days were spent washing, dressing, and feeding patients; conducting drug rounds; taking patients to rehabilitation activities; and performing medical tests. One nurse stated:

What chance do I stand when the staff on the acute floor at senior level do not understand selfcatheterization? We need more support in selfcatheterization education of staff by companies, as in my 30 hours, I cannot cover 5 wards (Interview, ID 1504).

The nurses observed that there were not enough selfcatheterization ambassadors and that the time for training nurses across wards was insufficient. Previously, time slots were dedicated to nurse-to-nurse training. Finding the time to take nurses off the floor is difficult, and high staff turnover means a continuous loss of skills and a degradation of best practices that is hard to make up for. Consequently, many nurses in the wards lack the confidence and skills needed to train self-catheterization patients - and this is only exacerbated by the substantial language barriers among the many foreign nurses. Sometimes, these problems result in unsuccessful training experiences for the patients and for the nurses, who feel pressured, misunderstood, and alone. At other times, it results in ambassadors being called on to train unknown patients in other wards. One nurse explained:

Patients are afraid of the unknown. Nonnativespeaking staff find it hard to explain self-catheterization in a way that reassures the patient and makes them comfortable, leaving the patient to think: 'No!

That is not for me. That sounds awful'(ID 1505).

These issues increase the existing pressure on nurses, further promote delays in learning about self-catheterization, and cause uncertainty for patients, who are often forced to take part in a very intimate procedure with an unfamiliar nurse.

\section{The complex interactions between nurses and patients}

Thus, although nurses often consider self-catheterization as the gold standard, it only is the best choice if it works for individual patients. Our results also reveal some obstacles for using self-catheterization from the nurses' perspective. Among patients who are perceived as potential self-catheterization candidates, the main obstacles are as follows: i) arm or shoulder fatigue, e.g., from wheelchair transfers; ii) taboos related to genitalia; iii) fear of self-inflicted injury and pain; iv) worries about wetness between catheterizations; v) physiological aspects, such as comorbidity and obesity; vi) lifestyle conflicts related to the relatively strict management regime of selfcatheterization (e.g., management of alcohol intake and situations without toilet access). The somewhat soft adherence approach to bladder management that characterizes nurses' culture allows for more patient pushback regarding self-catheterization. Treatment goals, choices, and routes are, to a large extent, centered on the patient's needs and wishes. However, this study's results also suggest that some nurses (particularly less experienced ones) find it quite hard to challenge patients' views when they do not coincide with their own. Below are some related statements from the nurses:

Patients come with a multitude of issues. Social issues, family background issues, bad hospital experience issues. And we inherit this and have to deal with it. The patients have little trust (WhatsApp, ID 1505).

I think we give our patients too many choices that may be ill-informed or do not encourage them to do the right thing. Self-catheterization is like tackling a gym session with a personal trainer. You know it is good for them in the long run but you hate the thought of doing it (WhatsApp, ID 1502).

As the nurses stated, patient care and treatment is rather complex due to the multitude of issues patients can have. This is critical in a treatment area that is often characterized by scared and overwhelmed patients with little trust and by a relatively high prevalence of mental and social difficulties. However, the nurses also deal with these patients professionally and find ways to tackle these issues.

\section{Culture and shifts in decision-making}

This study's results suggest that medical consultants are often primary decision-makers when it comes to bladder management. In the opinions of senior nurses in particular, this represents a shift in decision-making, as nurses once acted much more independently. Nurses find they are often better equipped than consultants to address treatment needs in this area, as they are closer to the patients and have more in-depth knowledge and hands-on experience. Thus, from the nurses' point of view, this shift not only undermines their authority and expertise but does not align with the best practices for bladder management. This study's results also indicate that medical consultants might have less positive perceptions of self-catheterization than nurses; as nurses (especially inexperienced ones) often find it hard to defend their views (when they contrast with the patients'), the choice of treatment implies a potential conflict. In relation to self-catheterization, some nurses found that patients were labeled with self-catheterization inappropriately or prematurely because consultants had taken the lead.

I have been closely involved in self-catheterization training for probably 15 years. I feel in recent times, consultants are pushing to become more involved in decision making where self-catheterizations are concerned. This causes conflict, as often patients are given conflicting guidance. Many 
times, the patient chooses to listen to the consultant as they feel [the consultant] must know more. Often, this is not the case. Then I am left to try and repair the damaged confidence and build trust (Interview, ID 1501).

This concept was validated by other patients:

It tends to be the consultant who broaches the subject with patients and nurses who explain and answer questions (Patient interview, ID 1503).

Yes, it was the consultant whom I talked to and seemed quite knowledgeable (Patient interview, ID 1507).

The nurses clearly perceive that they are becoming less influential, and established self-catheterization practices are consequently disappearing. The nurses also perceive that focus is often on bladder stabilization and health rather than on bladder management. From the nurses' points of view, the shift to medical consultants as the primary decision makers undermines the nurses' authority and expertise as well as the established best practices around bladder management.

\section{Conclusions}

The novelty of this article is the structured framework for using mobile ethnography and the emphasis on reflexivity when using, e.g., WhatsApp as an ethnographic method. The main conclusion is that the use of WhatsApp as a self-tracking tool can extend the methodological toolbox and support the possibility of in-depth data insights and the potential for increased triangulation so as to minimize bias. The use of WhatsApp for self-tracking within this study minimized both the researchers' presence in situ and the participants' recall bias.

Besides these overall advantages, we can also conclude that using mobile ethnography and WhatsApp requires much reflexivity and preliminary work to be beneficial. The nurses provided text messages, photos, and videos as part of their continuous communication in a very engaged way; this included complex contextual elements and was documented in real time. As part of the data collection, an almost friend-like communication developed between participants and researchers, with some very informal communication elements.

We conclude that this type of mobile ethnography provides dynamic interaction but needs to be very carefully handled, maintaining the General Data Protection Regulations while encouraging trust, engagement, and continuous data collection.

Another conclusion is that the data analysis associated with this method is rather time consuming, as the raw data is participant-driven and unstructured. This means that results based on mobile ethnography can be difficult to analyze due to the fragmented data structure. Therefore, carefully structured data analysis is needed, as much of the information is not relevant to the research.
The ethnographic approach applied to the given case study provided deep insights into specific elements within nurses' perceptions and practices for improved workflows and procedures when using and introducing self-catheterization for patients. Based on the results from this study, the management at Stoke Mandeville Hospital employed one extra nurse with a special focus on self-catheterization. From this study, it was rather clear that nurses perceived bladder management as not being properly prioritized during rehabilitation. Conversations about bladder management were often postponed and taken over by medical consultants due to a lack of resources or the absence of a rehabilitation mindset.

\section{References}

1. Yin R. Case study research: design and methods. 4th ed. Thousand Oaks, CA: Sage Publications; 2009.

2. Weld KJ, Dmochowski RR. Effect of bladder management on urological complications in spinal cord injured patients. J Urol 2000;163:768-72.

3. Krebs J, Wöllner J, Pannek, J. Risk factors for symptomatic urinary tract infections in individuals with chronic neurogenic lower urinary tract dysfunction. J Spinal Cord Med 2015;54:682-6.

4. Wyndaele J. Complications of intermittent catheterization: their prevention and treatment. J Spinal Cord Med 2002;40:536-41.

5. Coloplast continence life study review 2017/2018. Coloplast 2018, study 2017-18, Article 03. Humlebaek, Denmark: Coloplast; 2018. Available from: https:/www.coloplast. com/products/bladder-bowel/continence-life-study/2017/

6. Marcus GE. Ethnography in/of the world system: the emergence of multi-sited ethnography. Annu Rev Anthropol 1995;24:95-117.

7. Stickdorn M, Frischhut B, Schmid JS. Mobile ethnography: a pioneering research approach for customer-centered destination management. J Tour Anal 2014;19:491-503.

8. Hein W, O'Donohoe S, Ryan A. Mobile phones as an extension of the participant observer's self: Reflections on the emergent role of an emergent technology. Qual Market Res Int J 2011;14:258-73.

9. Bjørner T. Qualitative methods for consumer research: the value of the qualitative approach in theory and practice. Copenhagen: Hans Reitzels; 2015.

10. Spooncer F. Behavioural studies for marketing and business. Leckhampton: Stanley Thornes; 1992.

11. Hesse-Bieber SN. The practice of qualitative research: engaging students in the research process. 3rd ed. London: Sage; 2017.

12. Pink S. Situating everyday life. London: Sage; 2012.

13. Barton TD. Student nurse practitioners - A rite of passage? The universality of Van Gennep's model of social transition. J Nurs Educ Pract 2007; 7:338-47.

14. Hine C. Connective ethnography for the exploration of escience. J Comput Mediat Commun 2007;12:618-34.

15. Finkelman A. Professional nursing concepts: competencies for quality leadership. 4th ed. Burlington, MA: Jones and Bartlett; 2017.

16. Lupton D. The commodification of patient opinion: the dig- 
ital patient experience economy in the age of big data. Sociol Health Illn 2014;36:856-69.

17. Lupton D. The quantified self. Cambridge: Polity Press; 2016.

18. Johnson KB, Gadd C. Playing smallball: approaches to evaluating pilot health information exchange systems. J Biomed Inform 2007;40:S21-6.

19. Ziewitz M. Experience in action: moderating care in webbased patient feedback. Soc Sci Med 2017;175:99-108.

20. Balogh EP, Miller BT, Ball JR, eds. Improving diagnosis in health care. Washington, DC: National Academies Press; 2015.

21. Freihoefer K, Kaiser L, Vonasek D, Bayramzadeh S. Setting the stage: a comparative analysis of an onstage/offstage and a linear clinic modules. HERD 2017;11:89-103.

22. Weigl M, Müller A, Zupanc A, et al. Hospital doctors' workflow interruptions and activities: an observation study. BMJ Qual Saf 2011;20:491-7.

23. Pink S. Doing visual ethnography. London: Sage; 2013.

24. Atkinson P, Hammersley M. Ethnography: principles in practice. New York, NY: Routledge; 2007.

25. ICC/ESOMAR contents international code on market, opinion and social research and data analytics. Amsterdam: ESOMAR; 2016. Available from: https://www.esomar.org
26. Gulacti U, Lok U, Çelik M. Use of WhatsApp application for orthopedic consultations in the ED. Am J Emerg Med 2016;34:1305-7.

27. Sener TE, Butticè $S$, Sahin $B$, et al. WhatsApp use in the evaluation of hematuria. Int J Med Inform 2018;111:17-23.

28. Urry J. What we do whilst driving: towards the driverless car. In: Urry J, Grieco M, eds. Mobilities: new perspectives on transport and society. New York, NY: Routledge; 2016. pp 245-266.

29. Cummins S, Curtis S, Diez-Roux AV, Macintyre S. Understanding and representing "place" in health research: A relational approach. Soc Sci Med 2007;65:1825-38.

30. Kusenbach M. Go-alongs. In: Flick U, ed. The Sage handbook of qualitative data collection. London, UK: Sage Publications; 2018. pp 344-361.

31. Endeley RE. End-to-end encryption in messaging services and national security - Case of WhatsApp Messenger 2018. Int J Inf Secur 2018;9:95-9.

32. Creswell JW. Research design: qualitative, quantitative and mixed methods approaches. 4th ed. London, UK: Sage Publications; 2014.

33. Whittemore R, Chase SK, Mandle CL. Validity in qualitative research. Qual Health Res 2001;11:522-37. 